\title{
SEVERITY OF DEPRESSION AND ANXIETY AMONG CAREGIVERS OF CHILDREN WITH CEREBRAL PALSY AND THEIR CORRELATION WITH FUNCTIONAL CAPABILITIES OF THE CHILDREN
}

\author{
Sikandar Ali Khan, Fazal Ur Rahman Saeed*, Saeed Bin Ayaz** \\ Combined Military Hospital Gujranwala/National University of Medical Sciences (NUMS) Pakistan, *Armed Forces Institute of Rehabilitation Medicine/National \\ University of Medical Sciences (NUMS) Rawalpindi Pakistan, ${ }^{* *}$ Combined Military Hospital Jhelum/National University of Medical Sciences (NUMS) Pakistan
}

\section{ABSTRACT}

Objective: To evaluate the severity of depression and anxiety among caregivers of children having cerebral palsy and correlate severity with the type of cerebral palsy and functional capability of the child.

Study Design: A cross-sectional study.

Place and Duration of Study: Department of Psychiatry and Rehabilitation Medicine, Combined Military Hospital, Gujranwala, from Oct 2015 to Aug 2018.

Methodology: Through consecutive sampling, 186 caregivers diagnosed with anxiety and/or depression based on the diagnostic criteria of International Classification of Diseases version 10, and their cerebral palsy children were recruited. Symptom severity was assessed using Beck Depressive Inventory for depression and Beck Anxiety Inventory for anxiety. The functional capabilities of the children were assessed through gross motor function classification system (GMFCS). For correlation, Pearson's chi square test was used using SPSS version 20.

Results: The mean age was $30 \pm 3.3$ years. Fourteen $(7.5 \%)$ were fathers of cerebral palsy children and $172(92.5 \%)$ were mothers of cerebral palsy children. Majority of the cerebral palsy children $74(39.8 \%)$ had spastic diplegia and the functional level I of gross motor function classification system 53 (28.5\%). Most of the caregivers had mild anxiety and minimal depression (33.9\% and 38.7\% respectively). Significant correlation existed among the gross motor functional capability and the level of anxiety but not with depression $(p<0.01$ and $p=0.155$ respectively). No statistical association was found between the type of cerebral palsy and the level of anxiety or depression ( $p=0.240$ and $p=0.102$ respectively).

Conclusion: Most caregivers in our study had mild anxiety and minimal depression. Significant positive correlation existed between the level of anxiety and the gross motor functional capability.

Keywords: Anxiety, Caregiver, Cerebral palsy, Depression, Motor function.

This is an Open Access article distributed under the terms of the Creative Commons Attribution License (https://creativecommons.org/licenses/by-nc/4.0/), which permits unrestricted use, distribution, and reproduction in any medium, provided the original work is properly cited.

\section{INTRODUCTION}

Cerebral palsy $(\mathrm{CP})$ is a neuro developmental disorder with major physical and cognitive impairments due to damage to the developing brain during perinatal period or shortly after childbirth ${ }^{1}$. Prevalence of CP is 2.11 per 1000 live births among children born since $1985^{2}$. Families having children with CP face difficulties as the child is fully or partially dependent on the caregiver, which is mostly the mother ${ }^{1,3}$. Dependency of $\mathrm{CP}$ child has direct effects on physical, emotional, social, marital, and financial status of the primary caregiver or the mother ${ }^{3-6}$. These effects are more pronounced on caregiver due to personal closeness to the $\mathrm{CP}$ child 7 . Caregiving the child with CP is intense with specific demands like feeding, grooming, and mobility ${ }^{7}$. Graver disability inflicts greater impact on the caregiver.

As a child grows and gains weight, it poses

Correspondence: Dr Fazal Ur Rahman Saeed, Classified Specialist, Armed Forces Institute of Rehabilitation Medicine, Rawalpindi Pakistan Received: 12 Apr 2019; revised received: 28 Sep 2019; accepted: 05 Nov 2019 increased strain on the caregiver depending on the level of disability. Family of a child with CP especially mothers, face sense of responsibility and guilt feeling, which causes mothers to adopt behaviors that are directed to counter the disability of the child. Primary caregiver or mother of the $\mathrm{CP}$ child is psychologically neglected because she does not get adequate support from the relatives and friends for care of the disabled child ${ }^{8}$. She has trouble in maintaining balance between her abilities and demands for care tendered by the disabled child. This puts primary caregiver or the mother under lots of stress and, consequently, she starts to neglect her own needs leading to psychosocial problems and depression ${ }^{9}$. Studies have shown that primary caregiver or mothers with $\mathrm{CP}$ child have four times more incidence of depression as compared to normal population $^{10}$. There is a need to realize more and more about stress and strain faced by the caregivers and mothers of the children affected by CP. In developing countries like Pakistan, the resources are limited and daycare facilities are deficient. The stress and strain are increased manifolds as they are neither recognized nor apprecia- 
ted properly ${ }^{6}$. There have been studies ${ }^{11,12}$, to look for the frequency and severity of depression among children with $\mathrm{CP}$ and learning disabilities. However, more needs to be explored especially in relation to disability characteristics of the affected child. This study intended to correlate severity of depression and anxiety in primary caregivers of $\mathrm{CP}$ children with the type of $\mathrm{CP}$ and functional capability of the child.

\section{METHODOLOGY}

This cross-sectional study was conducted at the department of Psychiatry, Combined Military Hospital Gujranwala in liaison with the department of Rehabilitation Medicine from October 2015 to August 2018. A sample size of 180 was estimated via Epi Tools Epidemiological Calculator ${ }^{13}$, while keeping level of significance $5 \%$, confidence level $90 \%$, estimated true proportion $79 \% 14$, and $5 \%$ of absolute precision. We consecutively sampled 186 caregivers of children (age: 2-18 years) with $\mathrm{CP}$ who were diagnosed with anxiety and/ or depression based on the diagnostic criteria of International Classification of Diseases version 10 after approval from the hospital ethical committee. All inductees were interviewed after the informed written consent and their confidentiality was ensured. Children with other disabling diseases were not included.

Demographic details of the caregivers and children were documented. To assess the functional level of the children, Gross motor function classification system (GMFCS) was applied. GMFCS is a system used to categorize children with $\mathrm{CP}$ that classifies children younger than 12 years of age into five groups according to gross motor movements: group-I) Walks without limitations; group-II) walks with limitations; group -III) walks using a hand-held mobility device; groupIV) self-mobility with limitations; may use powered mobility; group-V) Transported in a manual wheelchair. Functions are defined according to four different age-groups and lower levels mean better functional capability. Children over 12 years of age were considered and assessed as 12 years old.

Detailed assessment and symptom severity was assessed using beck depressive inventory (BDI) for depression and beck anxiety inventory (BAI) for anxiety. BDI consists of 21 questions, each with four possible answers that are assigned a score ranging from 0-3. Higher scores indicate more severe symptoms. Total score is obtained by adding individual scores of 21 items and total score ranges from 0-63. The cut off score for presence of symptoms is 9 . It may be noted that $\mathrm{BDI}$ is for detecting depressive symptoms and not for diagnosing depression. Scores of 0-9 indicate minimal depression, 10-18 mild depression, 19-29 moderate depression, and scores of 30-63 indicate severe depressive symptoms. BAI consists of 21 items, scored on likert-type scale from $0-3$ where 0 is considered negative, 1 is judged as mild, 2 is deemed moderate, and 3 is considered severe. Total score of 0-7 reflects minimal anxiety and a score of 8-15 points toward mild anxiety. Score of 16-25 correlates with moderate anxiety and score of 26-63 compares with severe anxiety.

Data analysis was performed using Statistical Package for Social Sciences version 20. The data were described as numbers and percentages. For association and comparison pearson's chi square test was used. All the inferences were made at $95 \%$ confidence interval and $p$-values of $\leq 0.05$ were considered significant.

\section{RESULTS}

A total of 186 caregivers and children were included in the study. The mean age of the children was 5.1 \pm 2.4 years (range: $2-12$ years) while the mean age of the caregivers was $30 \pm 3.3$ years (range: $20-43$ years). In the study sample, $115(61.8 \%)$ were male children and $71(38.2 \%)$ were female children. Fourteen $(7.5 \%)$ caregivers were fathers of CP children and 172 (92.5\%) caregivers were mothers of $\mathrm{CP}$ children. All caregivers were married. Twenty (10.8\%) caregivers had to provide care to someone else in the family apart from the child while 166 (89.2\%) did not have such compulsion. The number of siblings, educational status of the caregiver, employment status of the caregiver, and financial status of the family are given in table-I.

With regards to the type of $\mathrm{CP}$ in children, 74 (39.8\%) had spastic diplegia, 56 (30.1\%) had spastic quadriplegia, and $45(24.2 \%)$ had spastic hemiplegia. Eleven $(5.9 \%)$ children had other types of CP. Gross motor functional capability level-I was present in 53 $(28.5 \%)$ children; 18 (9.7\%) children had level-II, 37 $(19.9 \%)$ children had level-III, 31 (16.7\%) children had level-IV, while 47 (25.3\%) children had level-V of functional capability. One hundred and twenty-five $(67.2 \%)$ caregivers had minimal to mild level of anxiety, 47 $(25 \%)$ had moderate, while 14 (7.5\%) had severe anxiety. One hundred and thirty-eight $(74.2 \%)$ caregivers exhibited minimal to mild depression, 32 (17.2\%) had moderate, while $16(8.6 \%)$ had severe depression (table-I).

After evaluating statistical correlation of gross motor functional deficit with the severity of anxiety and depression, a significant correlation was found with the level of anxiety but not with depression $(p$ 
Table-I: Demographic details of study participants.

\begin{tabular}{|c|c|}
\hline Characteristics & n (\%) \\
\hline \multicolumn{2}{|c|}{ Number of siblings of the cerebral Palsy child } \\
\hline None & $38(20.4)$ \\
\hline One & $92(49.5)$ \\
\hline Two & $18(9.7)$ \\
\hline Three & $20(10.8)$ \\
\hline Four & $11(5.9)$ \\
\hline More than four & $7(3.7)$ \\
\hline \multicolumn{2}{|c|}{ Educational status of the care giver } \\
\hline Illiterate & $3(1.6)$ \\
\hline Less than primary & $14(7.5)$ \\
\hline Primary & $134(72)$ \\
\hline Secondary & $20(10.8)$ \\
\hline High school & $14(7.5)$ \\
\hline University & $1(0.6)$ \\
\hline \multicolumn{2}{|c|}{ Employment status of the care giver } \\
\hline Employed & $27(14.5)$ \\
\hline Un-employed & $159(85.5)$ \\
\hline \multicolumn{2}{|l|}{ Family income } \\
\hline Poor & $27(14.5)$ \\
\hline Middle class & $152(81.7)$ \\
\hline High income & $7(3.8)$ \\
\hline \multicolumn{2}{|c|}{$\begin{array}{l}\text { Level of gross motor function deficit in the cerebral } \\
\text { palsy child }\end{array}$} \\
\hline Level-I & $53(28.5)$ \\
\hline Level-II & $18(9.7)$ \\
\hline Level-III & 37 (19.9) \\
\hline Level-IV & $31(16.7)$ \\
\hline Level-V & $47(25.2)$ \\
\hline \multicolumn{2}{|c|}{ Level of anxiety in the caregiver } \\
\hline Minimal & $62(33.3)$ \\
\hline Mild & $63(33.9)$ \\
\hline Moderate & $47(25.3)$ \\
\hline Severe & $14(7.5)$ \\
\hline \multicolumn{2}{|c|}{ Level of depression in the care giver } \\
\hline Minimal & $72(38.7)$ \\
\hline Mild & $66(35.5)$ \\
\hline Moderate & $32(17.2)$ \\
\hline Severe & $16(8.6)$ \\
\hline
\end{tabular}

of CP for the level of anxiety or depression $(p=0.240$ and $p=0.102$ respectively) (table-III).

\section{DISCUSSION}

The mean age witnessed for the sampled children in our study was $5.1 \pm 2.4$ years. A very similar mean age of $5.6 \pm 2.25$ years was observed in a Pakistani study carried out by Khan and colleagues ${ }^{15}$, in Rawalpindi. Another Pakistani study from Karachi has noted a slightly higher mean age of $6.57 \pm 1.9$ years $^{11}$. An Indian study carried out by Mehar et al ${ }^{3}$, in New Delhi had observed a nearer mean age of 4.6 years. The other demographic data in our study showed that most of the involved children were male and most of the primary caregivers were mothers belonging to the middle-class income group and had primary education. These outcomes and family characteristics show similarities in one or more aspects with the results of other studies organized by Masulani-Mwali et al ${ }^{16}$. Mehar and Tripathi ${ }^{3}$, and Basaran et $a l^{9}$. The majority of the participants $(90.1 \%)$ in the study by Mwali et al ${ }^{16}$, were mothers and $55.7 \%$ of them had secondary education only, while the largest representation (44.6\%) was from the lower socioeconomic group. Mothers represented $63 \%$ of the caregivers included by Mehar et $a l^{3}$, and male children constituted $57 \%$ of the sampled children. Basaran et $\mathrm{al}^{9}$, reported that $55.9 \%$ of the $\mathrm{CP}$ children taken account of were male. Most caregivers were mothers $(55.9 \%)$ and had merely the primary education $(57.3 \%)$. Most of the caregivers are expected to be mothers as per our cultural trends because mothers are considered primarily responsible for the care of children while fathers are considered breadwinners for the whole family and, therefore, pass their most time in the outdoors. All the caregivers in our study were married, which is also consistent with the cultural norms of our country as children out of wedlock are very rare

Table-II: Level of anxiety and depression in care givers with relation to level of gross motor function deficit of child.

\begin{tabular}{|c|c|c|c|c|c|c|c|}
\hline & & $\begin{array}{c}\text { Level-I } \\
\text { n }(\%)\end{array}$ & $\begin{array}{c}\text { Level-II } \\
\text { n }(\%)\end{array}$ & $\begin{array}{c}\text { Level-III } \\
\text { n ( } \%)\end{array}$ & $\begin{array}{c}\text { Level-IV } \\
\text { n }(\%)\end{array}$ & $\begin{array}{c}\text { Level-V } \\
\text { n (\%) }\end{array}$ & $p$-value \\
\hline $\begin{array}{l}\text { Level of } \\
\text { Anxiety in care } \\
\text { giver }\end{array}$ & $\begin{array}{l}\text { Minimal } \\
\text { Mild } \\
\text { Moderate } \\
\text { Severe } \\
\text { Total }\end{array}$ & $\begin{array}{c}20(32.3) \\
19(30.2) \\
12(25.5) \\
2(14.3) \\
53(28.5)\end{array}$ & $\begin{array}{c}8(12.9) \\
3(4.8) \\
7(14.9) \\
- \\
18(9.7)\end{array}$ & $\begin{array}{c}11(17.7) \\
11(17.5) \\
14(29.8) \\
1(7.1) \\
37(19.9)\end{array}$ & $\begin{array}{c}12(19.4) \\
13(20.6) \\
5(10.6) \\
1(7.1) \\
31(16.7)\end{array}$ & $\begin{array}{c}11(17.7) \\
17(27) \\
9(19.1) \\
10(71.4) \\
47(25.3)\end{array}$ & $<0.01$ \\
\hline $\begin{array}{l}\text { Level of } \\
\text { Depression in } \\
\text { care giver }\end{array}$ & $\begin{array}{l}\text { Minimal } \\
\text { Mild } \\
\text { Moderate } \\
\text { Severe } \\
\text { Total }\end{array}$ & $\begin{array}{c}22(30.6) \\
20(30.3) \\
9(28.1) \\
2(12.5) \\
53(28.5)\end{array}$ & $\begin{array}{c}10(13.9) \\
2(3) \\
4(12.5) \\
2(12.5) \\
18(9.7)\end{array}$ & $\begin{array}{c}16(22.2) \\
11(16.7) \\
6(18.8) \\
4(25) \\
37(19.9)\end{array}$ & $\begin{array}{c}14(19.4) \\
13(19.7) \\
3(9.4) \\
1(6.2) \\
31(16.7)\end{array}$ & $\begin{array}{c}10(13.9) \\
20(30.3) \\
10(31.2) \\
7(43.8) \\
47(25.3)\end{array}$ & 0.155 \\
\hline
\end{tabular}

$\leq 0.01$ and $p=0.155$ respectively) (table-II). Similarly, no statistically significant correlation existed with the type and considered a shame and sin in the Islamic and eastern society. 
Table-III: Level of anxiety and depression in care givers with relation to the type of cerebral palsy.

\begin{tabular}{|c|c|c|c|c|c|c|}
\hline Characteristics & & $\begin{array}{c}\text { Diplegic } \\
\text { Cerebral Palsy } \\
\text { n ( }(\%)\end{array}$ & $\begin{array}{c}\text { Hemiplegic } \\
\text { cerebral Palsy } \\
\text { n }(\%)\end{array}$ & $\begin{array}{c}\text { Quadriplegic } \\
\text { Cerebral Palsy } \\
\text { n (\%) }\end{array}$ & $\begin{array}{c}\text { Others } \\
\text { Cerebral Palsy } \\
\text { n (\%) }\end{array}$ & $p$-value \\
\hline $\begin{array}{l}\text { Level of Anxiety } \\
\text { in care giver }\end{array}$ & $\begin{array}{l}\text { Minimal } \\
\text { Mild } \\
\text { Moderate } \\
\text { Severe }\end{array}$ & $\begin{array}{c}29(46.8) \\
28(44.4) \\
14(29.8) \\
3(21.4) \\
\end{array}$ & $\begin{array}{c}11(17.7) \\
15(23.8) \\
13(27.7) \\
6(42.9) \\
\end{array}$ & $\begin{array}{l}17(27.4) \\
18(28.6) \\
18(38.3) \\
3(21.4) \\
\end{array}$ & $\begin{array}{l}5(8.1) \\
2(3.2) \\
2(4.3) \\
2(14.3) \\
\end{array}$ & 0.240 \\
\hline $\begin{array}{l}\text { Level of } \\
\text { Depression in } \\
\text { care giver }\end{array}$ & $\begin{array}{l}\text { Minimal } \\
\text { Mild } \\
\text { Moderate } \\
\text { Severe }\end{array}$ & $\begin{array}{c}28(38.9) \\
33(50) \\
9(28.1) \\
4(25)\end{array}$ & $\begin{array}{c}14(19.4) \\
16(24.2) \\
7(21.9) \\
8(50)\end{array}$ & $\begin{array}{c}24(33.3) \\
15(22.7) \\
14(43.8) \\
3(18.8)\end{array}$ & $\begin{array}{c}6(8.3) \\
2(3) \\
2(6.2) \\
1(6.2)\end{array}$ & 0.102 \\
\hline
\end{tabular}

Regarding type of $\mathrm{CP}$, we found that maximum number of the children had spastic diplegia (39.8\%). Khan et al also observed spastic diplegia as the most prevalent $(33.3 \%)$ type of $\mathrm{CP}$ in their study ${ }^{15}$. Altindag et $a l^{5}$, and Yilmaz et $a l^{8}$, in two Turkish studies, and Nazi et $a^{17}$, in an Iranian study, confirmed above findings by reporting spastic diplegia in the maximum number $(40 \%, 39.7 \%$, and $50 \%$ respectively) of recruited children. On the other hand, two Korean studies by Yun ${ }^{18}$, and $Y_{0 o}{ }^{19}$, had observed spastic quadriplegia to be the most commonly identified type of CP $(49.1 \%$ \& $52.5 \%$ respectively). This variation probably results from the genetic preferences or the environmental factors.

The commonest functional level of GMFCS detected by us was level-I (28.5\%). Türkoğlu et al ${ }^{20}$, labelled level-II as the most frequent $(29.9 \%)$ functional level. Altindag et al ${ }^{5}$, described level-III to be the most common. Yun ${ }^{18}$, and Yoo $^{19}$, stated that level-IV of GMFCS was the most frequent level. Nazi et al ${ }^{17}$, had observed level-IV as the most repeated functional level in children with $\mathrm{CP}$, while Yilmaz and colleagues, reported Level-V as the most common functional level.

Basaran et al , demonstrated that level of education, financial constraints, lack of recreation, and social isolation are related to stress, exhaustion, and development of mental health problems in caregivers of $\mathrm{CP}$ children. Mothers of $\mathrm{CP}$ children mainly bear the burden of care giving, which leads to deterioration of psychosocial wellbeing and has ill effects on children too. Though we included only the caregivers already diagnosed with anxiety and/or depression, the incidence of anxiety and depression seems quite high among caregivers of disabled children in the medical literature. Fahim et al ${ }^{12}$, reported an incidence of $89.6 \%$ while Mbugua et $a^{14}$, and Dambi et $a l^{6}$, reported incidences of $79 \%$ and $78 \%$ in caregivers of the children with disabilities, which were attributed to long term stress.
Majority of the caregivers had minimal to mild level of anxiety and depression and very few exhibited severe levels of anxiety and depression. These results indicate that anxiety and depression in caregivers of $\mathrm{CP}$ child might have relation to the type of CP. Results of our study though, do not demonstrate any relationship between anxiety and depression and the type of $\mathrm{CP}$. Türkoğlu et al20, on the contrary, noted that intellectual impairment and type of $\mathrm{CP}$ were correlated with the mental health of caregiver of the $\mathrm{CP}$ child. Terzi et $a l^{1}$ also, demonstrated that mental health of the caregiver of $\mathrm{CP}$ child might have correlation with the type of $\mathrm{CP}$.

We found a significant effect of severity of gross motor functional deficit on the development of anxiety but not on the depressive symptoms. Tuzun et al21. Chen et $a l^{22}$, and Unsal-Delialioglu et $a l^{4}$, also noted that there was no correlation between severity of anxiety and depressive symptoms and quality of care given by the caregiver of $\mathrm{CP}$ child. We found that anxiety and depression were higher in level I gross motor functional deficit which is contrary to the logical interaction i.e. anxiety and depressive symptoms are expected to be more in caregivers of the children with worse functional capability. On the other hand, Basaran et al ${ }^{9}$, in his study, noted that anxiety and depression were marked in the caregivers of CP child who had level IV and level $\mathrm{V}$ gross motor functional deficit indicating that severity of impairment predisposes caregiver to the development of anxiety and depression. Yoo ${ }^{19}$, endorsed results of Basaran et al ${ }^{9}$, and concluded that caregivers' quality of life (QoL) was worse and their depression scores were significantly higher as the children's motor functioning was impaired more severely. Yun ${ }^{18}$, also mentioned similar conclusion and stated that children's motor function affects caregivers' QoL in not only physical but also psychological sides. Thus, if parents are not able to meet the challenges of providing care for their $\mathrm{CP}$ child due to psychiatric disor- 
ders, the required level of child functioning will not be achieved and the QoL of the child shall be reduced ${ }^{23}$.

Focusing on the general and holistic medical paradigms, more attention needs to be given to the environments of patients and caregivers along with their health status, duration of care, and economic status. Caring training for caregivers of children with $\mathrm{CP}$ has a positive effect on caregiver's mental health and the participation of children in activities of daily living and their fine and gross motor function ${ }^{24}$. In addition, planned care for children with $\mathrm{CP}$ involving psychotherapists in a team-based rehabilitation can improve caregivers' QoL and mental health. It is important to keep in mind that our cross-sectional study has not established this causal relationship.

This study had a couple of limitations. As this was a descriptive cross-sectional study, therefore, causal relationship could not be established. Furthermore, other confounding factors to the development of anxiety and depression could not be accounted for.

\section{RECOMMENDATIONS}

Psychological needs of caregivers of functionally impaired children should be given due attention as they are more vulnerable and predisposed to develop mental health problems. Improvement in the psychological support of caregivers along with addressing comprehensive rehabilitation needs of children with $\mathrm{CP}$ can ensure good QoL for the child and caregiver collectively.

\section{CONCLUSION}

Most caregivers in our cohort had mild anxiety and minimal depression. Significant positive correlation existed between the level of anxiety and the gross motor functional capability.

\section{CONFLICT OF INTEREST}

This study has no conflict of interest to be declared by any author.

\section{REFERENCES}

1. Terzi R. Musculoskeletal system pain and related factors in mothers of children with cerebral palsy. Agri 2016; 28(1): 18-24.

2. Sellier E, Platt MJ, Andersen GL, Krägeloh-Mann I, De La Cruz J, Cans C. Surveillance of cerebral palsy network. decreasing prevalence in cerebral palsy: a multi-site european population-based study, 1980 to 2003. Dev Med Child Neurol 2016; 58(1): 85-92.

3. Mehar H, Tripathi DR. Psychological aspects of parents and developmental profile of children with cerebral palsy. J Disabil Manag Rehabil 2017; 2(2): 59-63.

4. Unsal-Delialioglu S, Kaya K, Ozel S, Gorgulu G. Depression in mothers of children with cerebral palsy and related factors in Turkey: a controlled study. Int J Rehabil Res 2009; 32(3): 199-204.
5. Altindag Ö, Işcan A, Akcan S, Koksal S, Erçin M, Ege L. Anxiety and Depression Levels in Mothers of Children with Cerebral Palsy. Turk J Phys Med Rehab 2007; 53(2): 22-24.

6. Dambi JM, Jelsma J, Mlambo T. Caring for a child with cerebral Palsy: the experience of Zimbabwean mothers. Afr J Disabil 2015; 4(1): 168-72.

7. Vicentic S, Sapic R, Damjanovic A, Vekic B, Loncar Z, Dimitrijevic I, et al. Burnout of formal caregivers of children with cerebral palsy. Isr J Psychiatry Relat Sci 2016; 53(2): 10-15.

8. Yilmaz H, Erkin G, Nalbant L. Depression and anxiety levels in mothers of children with cerebral palsy: a controlled study. Eur J Phys Rehabil Med 2013; 49(6): 823-27.

9. Basaran A, Karadavut KI, Uneri SO, Balbaloglu O, Atasoy N. The effect of having a children with cerebral palsy on quality of life, burn-out, depressionand anxiety scores: a comparative study. Eur J Phys Rehabil Med 2013; 49(6): 815-22.

10. Alaee N, Shahboulaghi FM, Khankeh H, Kermanshahi SMK. Psychosocial challenges for parents of children with cerebral palsy: A qualitative study. J Child Fam Stud 2015; 24(7): 2147-54.

11. Kumar R, Lakhiar MA, Lakhair MA. Frequency and severity of depression in mothers of cerebral palsy children. J Liaquat Uni Med Health Sci 2016; 15(3): 147-51.

12. Fahim M, Khan FA, Nizami AT. Frequency of depression in mothers of learning disabled children. J Islamabad Med Dent Coll 2017; 6(2): 113-16.

13. EpiTools. Epitools-Epidemiological Calculators. Aus Vet. [Internet] Available at: http://epitools.ausvet.com.au/content. php?page=1Proportion. [Accessed 29 December 2018] .

14. Mbugua MN, Kuria MW. The prevalence of depression among family caregivers of children with intellectual disability in a rural setting in Kenya. Int J Family Med 2011; 2011(2): 534513-18.

15. Khan AA, Ahmad K, Ayaz SB, Ayyub A, Akhlaq U. Cerebral palsy in Pakistani children: A hospital based survey. Cukurova Med J 2014; 39(4): 705-11.

16. Masulani-Mwale C, Kauye F, Gladstone M, Mathanga D. Prevalence of psychological distress among parents of children with intellectual disabilities in Malawi. BMC Psych 2018; 18(1): 146-50.

17. Nazi S, Shafaroodi N, Lajevardi L, Mehraban AH, Yazdani F, Hosseinzadeh S. Life balance of mothers of children with cerebral palsy. Int J Clin Med 2017; 8(11): 583-94.

18. Yun CK. Relationship between the quality of life of the caregiver and motor function of children with cerebral palsy. Phys Ther Rehabil Sci 2017; 6(1): 26-32.

19. Yoo JN. Correlations among motor function, quality of life, and caregiver depression levels in children with cerebral palsy. J Korean Phy Ther 2016; 28(6): 385-92.

20. Türkoğlu S, Bilgic A, Türkoğlu G, Yilmaz S. Impact of symptoms of maternal anxiety and depression on quality of life of children with cerebral palsy. Noro Psikiyatr Ars 2016; 53(1): 49-54.

21. Tüzün EH, Guven DK, Eker L. Pain prevalence and its impact on the quality of life in a sample of Turkish children with cerebral palsy. Disabil Rehabil 2010; 32(9): 723-28.

22. Chen $\mathrm{CM}$, Chen $\mathrm{CY}, \mathrm{Wu} \mathrm{KP}$, Chen CL. Motor factors associated with health-related quality-of-life in ambulatory children with cerebral palsy. Am J Phys Med Rehabil 2011; 90(11): 940-47.

23. Soliman RH, Altwairqi RG, Alshamrani NA, Al-Zahrani AA, AlTowairqi RM, Al-Habashi AH. Relationship between quality of life of children with cerebral palsy and their mothers' depression and anxiety. Saudi J Health Sci 2019; 8(1): 1-5.

24. Nobakht Z, Rassafiani M. Review of caring training for caregivers of children with cerebral palsy. Sci J Rehabil Med 2016; 5(3): 175-83. 